KATARZYNA STEMPLEWSKA-ŻAKOWICZ $^{1}{ }^{1}$, BARTOSZ ZALEWSKI ${ }^{2}$, HUBERT SUSZEK ${ }^{3}$, DOROTA KOBYLIŃSKA ${ }^{3}$, BARTOSZ SZYMCZYK ${ }^{1}$

${ }^{1}$ Helena Chodkowska University of Management and Law, Warsaw

${ }^{2}$ University of Social Sciences and Humanities, Warsaw

${ }^{3}$ University of Warsaw

\title{
THE DISCURSIVE MIND MODEL
}

The paper proposes the model of discursive mind and describes the cognitive architecture of the dialogically structured mind. The model draws on Hermans' (1999) theory of the dialogical self (DS) and Wertsch's (1991) vision of mind as a "tool kit" with socio-cultural instruments, and also on the socio-cognitive approach to personality in experimental psychology. An I-position is understood here as an active totality of experience, shaped in a particular social context and represented in a separate representation module. There are many modules in the mind because in the course of socialization, the individual comes across many different social contexts. The described model and its preliminary empirical verification not only gives support to the DS theory, but can also be a leverage of its contribution to general theories of mind stemming from other theoretical traditions.

Key words: dialogical self, positioning, I-position, cognitive architecture, discursive mind, shared knowledge, cognitive-affective resources

In this article we present our Model of the Discursive Mind ${ }^{1}$. We describe theories that served as a basis for the model, taken from both the social cognitive approach to personality and discursive and dialogical concepts.

Address for correspondence: Hubert Suszek, Faculty of Psychology, University of Warsaw, Stawki 5/7, 00-183 Warsaw, Poland. E-mail: hubert.suszek@psych.uw.edu.pl

${ }^{1}$ The shorter versions of the model were presented in Stemplewska-Żakowicz et al. (2009) and Stemplewska-Żakowicz et al. (2010). The first cited article was written in Polish and was targeted at a Polish audience. The second one was published in the International fournal for Dialogical Science which is representative for dialogical science itself but not dedicated to describing more general psychological topics. In the present paper we present a more elaborate version of the model and discuss its reference to the dialogical self theory in greater depth. At the same time we wanted to reach readers from outside the field of dialogical science. 
Referring to the classical differentiation described by James, it can be stated that contemporary theories of self show the multiplicity of its object-oriented aspect, but are scarcely interested in the multiplicity of the subject-oriented aspect of self. Greenwald and Pratkanis (1984) - with the help of the computer metaphor - gave modern meaning to James' differentiation as a distinction between data (declarations) and process (procedures). Since then, the subject-oriented aspect of self can no longer be thought of as metaphysical or scientifically immeasurable. Indeed, in the last two decades we can observe a considerable increase of researchers' interest in the subject-oriented aspect of self, yet they do not refer to the idea of the multiplicity of the subjective self. As far as we know, no theoretical model that would thoroughly describe this idea has so far been put forward in mainstream psychology. However, it seems that the idea of the multiplicity of the subjective self could open quite novel perspectives on many psychological phenomena.

The discursive mind model presented in this paper was proposed by Katarzyna Stemplewska-Żakowicz (2004). The reason behind the development of this model was to adapt the Dialogical Self Theory to the requirements of experimental research. It draws on earlier concepts of the discursive mind developed by Stemplewska-Żakowicz (2001), which have similar inspirations in the dialogical self theory, and at the same time refers to social-cognitive approaches.

\section{Assumptions of the discursive mind model}

The idea of the discursive organization of the cognitive system, inspired by Vygotsky's (1982) and Bakhtin's (1984) ideas and social constructionists' concepts (Berger \& Luckmann, 1966), combined with other ideas of discursive psychology, forms the foundation for the model described in this paper. According to this view, there are a number of holistic modules of representation which exist in our mind. They have relative autonomy and every module is related to a specific social context, present in one's history of socialization. As they are formed by different ways of giving meaning to personal experience, each of the modules contains specific cognitive-affective resources. The important parts of the social contexts in which these patterns of naming and organizing experience are formed include relationships with significant others, influential groups and social backgrounds (Hermans, 1999; Wertsch, 1991).

Based on the idea outlined above, we present three key assumptions of our discursive mind model:

1. the modular character of a person's knowledge structures;

2. the social origin of a person's knowledge structures;

3. the specificity of knowledge structures for the social context from which they stem. 
The first two of these assumptions are shared among a variety of contemporary theories; however, the third assumption, which is essential for the model presented here, has so far not been an important subject of interest in mainstream psychology.

\section{Modularity of personal knowledge structures in modern psychological theories (assumption one)}

The first assumption - about the modular character of the cognitive system - can be found in a variety of approaches (Epstein, 1991; Fodor, 1983; Gazzaniga \& LeDoux, 1978; Greenwald, 1982; Minsky, 1985; Nowak, Vallacher, Tesser, \& Borkowski, 2000; Cosmides \& Tooby, 1992). Most generally, it can be understood as referring to the idea, widely accepted nowadays, of cognitive structures being organized as systems of schemas. It started to be recognized in theories of self when the concept of self schemas was first introduced by Markus (1977), who showed in her studies that the activation of a schema referring to a particular field of knowledge makes it easier to state opinions and make decisions in this field. It also helps remember information related to this field of knowledge and to predict future behavior.

Jerry Fodor (1983) was the first to describe the mind as a structure composed of modules. Criticizing computer metaphors of mind, according to which the whole mind is engaged in processing a particular piece of information, he (Fodor, 2000) pointed out that this kind of activity is energy-consuming and thus uneconomical and unnecessary in efficient operations. His concept of module (Fodor, 1983) describes a structure specialized in dealing with a particular class of stimuli and thus processing a particular kind of information faster than general structures as well as engaging less cognitive resources. Fodor's concept (1983) focused on basic processes not requiring the engagement of attention processes or working memory and mostly referring to perception (face recognition, sound to language structure transcript). Processes of this kind run automatically, preparing data which are later integrated at a higher level by non-modular central processes such as thinking. A module accepts only external stimuli of one kind and ignores other stimuli, remaining closed to their access; it works automatically, which means that once it is activated it continues to work until it has completed its task (Fodor, 1983). Critical followers of Fodor's ideas, Cosmides and Tooby (1994), describe modules as if they were built according to the principle of best adaptation, working fast and automatically, thus being time-efficient and saving energy needed for making decisions, often operating directly and continuously from registering a stimulus to initiating behavior.

In our model we assume that the adaptive structure of the mind is composed of many specialized information processing subsystems, strictly related to and dependent on the topic of the information and operating automatically. Modules are partly closed, as defined by Cosmides and Tooby (1994): They remain latent and closed to information stored in a different code than the one processed by the particular module, although they remain open to information encoded using the same code or a code similar to the one assigned to the module. 
Fodor (1983) made a distinction between vertical and horizontal mind structures, calling them longitudinal modularity and transversal modularity, respectively. This brings to mind a structural division of modules into upper and lower levels, with different parallel modules existing at each level. This idea can be well clarified using a similar hypothesis, though different in its origins and inspirations, namely the levels of processing proposed by Anthony Greenwald $(1982,1988)$. For Greenwald (1982), the cognitive system comprises subsystems organized in consecutive levels. These subsystems are information processing units that operate using different processing codes and are specialized to deal uniquely with information encoded in the same code. These subsystems are organized as bottom-up levels, starting with the lowest up to the highest, where conscious thinking takes place. Greenwald (1988) introduces two conditions for the subsystems to be independent, partly limiting the exchange of information between them. These are differences in code types and limitations in a subsystem's access to knowledge stored in another subsystem. The main barrier in information exchange occurs between the procedural and declarative codes. Only a part of the information processed at lower levels, operating in procedural codes, temporal-sensual in character (i.e. motor), becomes recognized and translated into imaginative code, eventually becoming accessible to one's non-verbal insight. Then, some even smaller part is further recognized and encoded in verbal code in order to become a part of the conscious declarative knowledge of the subject. The hypothesis of levels of processing clarifies the processes of representing one's experience, in which pieces of experience are retained at lower levels and cannot be brought to the consciousness (in other words: represented in verbal code), but nonetheless influence feelings, states or behavior. This kind of information processing is described in literature as implicit social cognition or automatic information processing (Bargh, 1994, 1999; 2006; Chen \& Bargh, 1997; Greenwald \& Banaji, 1995; Stemplewska-Żakowicz, 2004; Underwood, 1996) and can be found in many theories, e.g. subsystems of information processing or computer-based simulations of the modular structure of the mind (Nowak et al., 2000).

The concept of levels of representation makes it possible to pose a question similar to Fodor's above-mentioned question addressed to classical psychology of the mind: Can representations at those levels be perceived as a complete tool, processing a whole range of information, or is it required to have specialized and independent units? Can processing be more effective? This draws our attention to longitudinal modularity: the vertical division crossing the horizontal levels. These longitudinal modules operate using separate, specific discursive codes we describe here together with the third assumption.

\section{Social origin of personal knowledge structures (assumption two)}

The second assumption is based on the proposition that information is processed by knowledge structures that stem from the social environments of a par- 
ticular person. Similarly to the first assumption, this one is also widely described in socio-cognitive personality theories (Bandura, 1999; Pervin \& John, 2001), social cognition concepts (Forgas, 1981; Forgas \& Williams, 2002; Moskowitz, 2005; Underwood, 1996), social constructionism (Berger \& Luckmann, 1966) and in still developing theories of shared reality (Hardin \& Higgins, 1996; Jost \& Kruglanski, 2002). The social environment means not only a source of stimuli related to a person's social activity but also a source of ways of processing and storing social information. Knowledge from cognitive and communication psychology helps describe the role of interpersonal activities in shaping the content of personal knowledge and the structures in which this knowledge is stored (Higgins, 2000).

A fine example of an approach based on the assumption described here is the relational self theory put forward by Susan Andersen and Serena Chen (2002). According to the authors, the self-structure is composed of a number of relational schemas developed in the course of long-term relations with significant others (e.g. parents) whose representations are saved in the cognitive system. Each representation of a significant other is linked with a particular representation of self, and these pair packages of co-linked representations create the schemas of the relational self, constantly available, different in content but launched by different classes of external stimuli. Connections between knowledge about self and knowledge about others develop due to affective processes - they are nurtured by the long-term, emotional and motivational occupation with significant others. The theory shows how separate units of representation develop, shaped by relations with others, and then how these schemas set directions for a person's interpretation of experience.

Daniel Cervone's KAPA (Knowledge-and-Appraisal Personality Architecture) model is a similar concept, although it focuses on the meaning of interaction between a person and a situation as a foundation of the cognitive system and, at the same time, a person's inner lability. Cervone (2004) expands the vision of self as being composed of schemas by describing the rules governing the availability of knowledge structures, as posited by the social cognition approach. He sees personality as a structure of cognitive affective units forming regular patterns of experience interpretation (Cervone, 2004). These units comprise knowledge - representations of different elements of the world and of the person in his/her mind - and appraisal, which is a sort of dynamic network connecting the units. Relations with others are not the only source of cognitive affective schemas - they also draw from wider external contexts. Each piece of knowledge is attributed to a particular situational context and affects the appraisal, which occurs within a person only in a context specific for the schema. In addition, people differ in the way in which the network connecting the schemas and the contexts is shaped. The contexts can also differ idiosyncratically - two persons bearing the belief that they are shy can have different subjective perspectives on the social contexts in which such a trait as shyness is important and thus be or feel shy in different situations 
and for different reasons. Cervone's model (2004) is a challenge for the experimental method, which relies on standardized stimuli evoking reactions among participants, because the standardization of the stimuli is disabled by the model itself. In his research on people who smoke, the author came up with a method based on priming in which the priming stimuli were developed individually for each participant and, at the same time, were equivalent among all participants (Cervone et al., 2008). A similar methodology was suggested by Cervone in regard to research on activating I-positions in the dialogical self theory2, which can be a solution better than trying to activate the same or similar I-positions among all the participants, assuming that they exist in the participants' repertoire (Suszek, Kobylińska, Stemplewska-Żakowicz, \& Szymczyk, 2010).

Social cognition theories indicate that a person brings earlier attitudes to the cognition process and that these attitudes influence information processing in regard to the properties of this object, such as its description, classification or rating its importance. The knowledge stored in the mind determines patterns of interpreting signals from the environment (Forgas, 1981) by means of selective attention, information processing limits in the mind, reduction of the amount of data processed in case of complex objects of cognition (such as humans or social situations), or other well-known cognitive effects - priming effect, primacy effect or framing effect (Moskowitz, 2005). Currently, the idea of processes of social negotiation and sharing cognitive content, the availability of which depends on the external relational context, is widely accepted (Moskowitz, 2005). According to social cognition theories, knowledge referring to the object of cognition is determined mostly by real features of the object and can be modified only by elements that are brought into the cognition process by a particular person. The third assumption of the discursive mind model is contrary to this idea: not the object of cognition, but the cognitively active subject is the key factor in the whole process of cognition.

\section{Toward the specificity of knowledge structures for the social context - discursive approach concepts (assumption three)}

Although overlooked or undervalued by mainstream psychology, the third assumption mentioned above is still present in the concepts of social constructivism and discursive psychology. However, as these theories - e.g. Rom Harré's theory of positioning (Harré \& Gillett, 1994; Harré \& van Langenhove, 1999) or the influential ideas of Kenneth Gergen (1991, 2009), Derek Edwards and Jonathan Potter (1992) and Michael Billig (1996) - usually reject experimental methodology and discard traditional notions such as cognitive representation, they also do not put forward any precise model of the mind's architecture. Thus, no specific hypothesis that could later be verified can be drawn from these theories. The contrast between the discursive ideas and the personality and social cognition

\footnotetext{
${ }^{2}$ Information from face-to-face conversation.
} 
theories mentioned above can be perceived as another exemplification of the general interaction-cognition gap in the social sciences recognized by Teun van Dijk (2007, see also Jost \& Kruglanski, 2002).

In an attempt to fill this gap, van Dijk $(1989,2008)$ characterized two different mental models needed to explain the act of text processing: the text model and the context model. While the text model represents the data currently being processed, the context model works as an overriding script-like structure representing the social situation (the subjective meaning of it) in which a particular act of information processing takes place. The text model activity is thus continuously controlled and shaped by the context model. Therefore, despite changing conditions, the developing discourse maintains its suitability. We think that it is similar to a process in which a specific perspective of an I-position regulates and adjusts the ongoing information processing. It is the processing itself that both the subject and the researcher tend to focus on when studying the person's activity. The specific perspective of the I-position, however, is omitted from conscious thinking. Nonetheless, a context model, or as in the DST, the I-position works as an implicit determinant of the actual internal activity. Van Dijk's (2008) concept of context model imposes a wider perspective on researchers, in a similar way as the concept of an I-position did. This difference of perspectives provides scope for the integration of these theories in the discursive mind model

We assume that the activation of knowledge structures depends on the current social relational context, thus relational factors play a key role in this process. It is possible that the object of the knowledge itself also influences the processing of information (such as schemas or scripts); however, we would like to stress that the situational context activates the subject of perception, which becomes a dominant figure in processing knowledge (Stemplewska-Żakowicz et al., 2010).

The transversal modularity described above refers to levels of representation divided by barriers in the flow of information. The second assumption indicates that the external relational context in which the cognitive activity takes place and the information stored before in the mind are the criteria of activating knowledge concerning the object of cognition. If different contexts activate packages of representations linked with these contexts and present in the mind, then it is unlikely that information is processed entirely on one level of representation.

According to our model's assumption, units of knowledge that develop in the mind are coherent in a particular frame of social reference but different from units developed in other frames of reference. The source of knowledge is thus a criterion of development and differentiation of the longitudinal modules. Each level of representation is divided into further elements. Starting from the lowest levels, which are the earliest in development, a child learns ways of constructing meaning from the closest environments; the number of social contexts rises together with the development process. Even the lowest levels store records of different patterns of interpreting the incoming stimuli (pragmatic and semantic) existing 
in different codes. These codes form borders of a particular system of meaning and limit the possibility of information exchange. On the highest level, there are well developed, internally coherent longitudinal modules - which are similar to the I-positions in the dialogical self theory (Stemplewska-Żakowicz et al., 2010).

\section{On the role of the subject}

We assume that every piece of knowledge is "someone's", therefore for every piece of knowledge, we can ask who the subject of that knowledge is. There is no knowledge without a subject3, just as there is no novel or handbook without an author. In addition, the social features of the subject are imprinted in the content and shape of the knowledge shared by it, as analysts of discourse argue (Van Dijk, 1997). For the model proposed here, the differentiation between the subject of knowledge and the object of knowledge is fundamental. It seems that the majority of research and concepts focus on the former aspect of the social cognition process, while the latter remains relatively unknown and is not studied. The role of the subject is properly appreciated by those researchers in the social cognition approach who take into account the inter-subjective nature of the cognition process (Higgins, 2000).

The contemporary processes of globalization (Hermans \& Hermans-Konopka, 2010) and the complexity of the world not only determine that a person is involved in a variety of relations or is a member of a variety of groups, but also require the ability to hold multiple perspectives of interpreting one's experience and to adjust these perspectives appropriately to different external contexts. This internal variety and variability, according to the theses of the model hereby presented, is reflected in the architecture of the cognitive system. The diversity of a person's knowledge stemming from different social contexts is recorded and stored in different modules of representation, which form the cognitive system. These modules are subject-oriented, which means that the subject of knowledge is a more important (although likely to be implicit) criterion of knowledge aggregation than its object; for it is a book's author that is a more significant attribute of knowledge creation than its title. Thus, different modules may contain different pieces of knowledge, even if they all concern the same object.

\section{Cognitive architecture of the discursive mind}

What are the consequences of this for the cognitive architecture of the mind? Let us consider the example shown in Figure 2, which derives from an introspection of one of the authors (the first one) of this paper. It shows the subjective meaning of the concept of "a dog", which turns out to have a slightly different

\footnotetext{
${ }^{3}$ Of course, we ought to keep in mind that there are theories and concepts which allow this possibility, such as Plato's idealism or Popper's "third world".
} 
Figure 1. Structure of the notion of "a dog” according to Rosch's concept

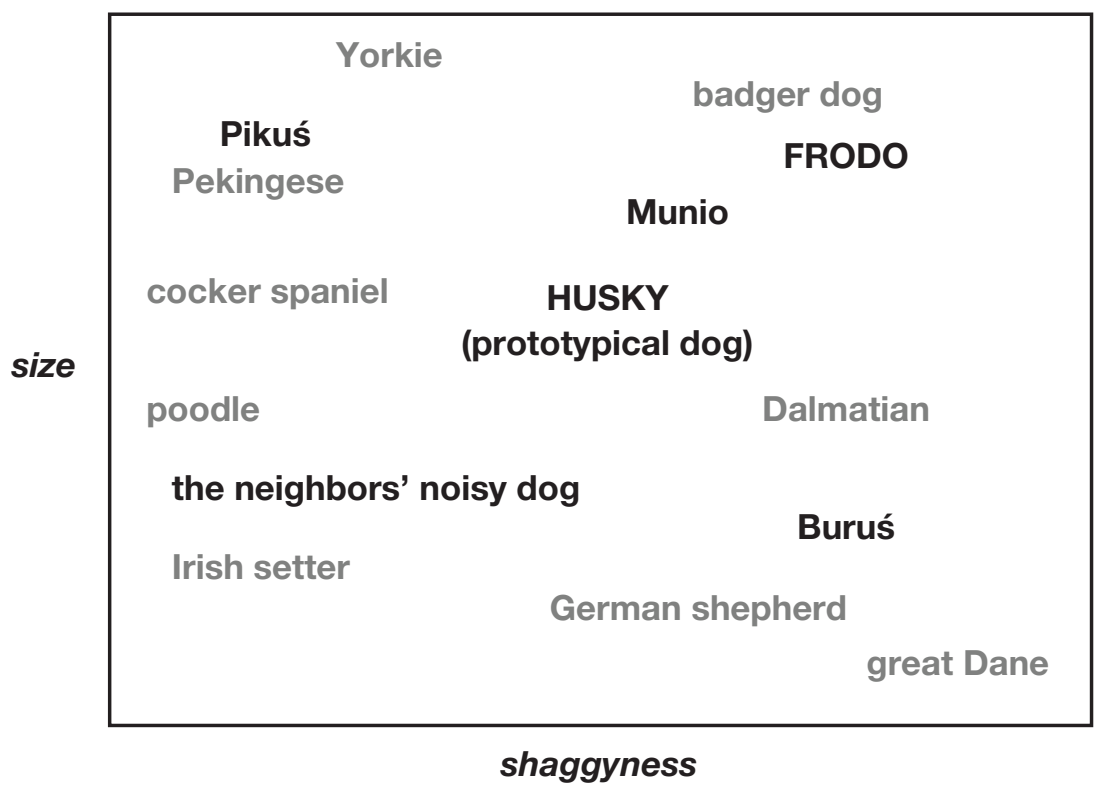

structure from a discursive mind concept perspective than it would have according to the contemporarily acknowledged idea of natural concepts (Rosch, 1978) (Figure 1).

Natural concepts consist of a prototype and a number of exemplars of greater or smaller resemblance to the prototype. The resemblance can be interpreted as a distance and on its basis we can predict how fast the concept of "a dog" is activated when we are exposed to different exemplars of dogs' images as more or less prototypical exemplars of this concept. For example, Figure 1 implies that the time for recognizing a given object as a dog should be shorter when a Dalmatian's image is presented and longer for an image of a badger dog or a Pekingese. In this case it is irrelevant from which social context the knowledge of different examples of a dog comes - it is universal and organizes all information on dogs stored by a given person. The whole process looks different from the perspective of the discursive mind model, in which - as shown in Figure 2 - the exemplars of "a dog" concept are organized in three different circles. Each circle contains representations of different dogs, which are constructed in certain social contexts. In this introspective example the "owner" of knowledge about dogs discovered that there are at least three different concepts that play a major role: a dog breeder's handbook studied carefully when she was young (the author 
Figure 2. Structure of the notion of "a dog" according to the discursive mind model
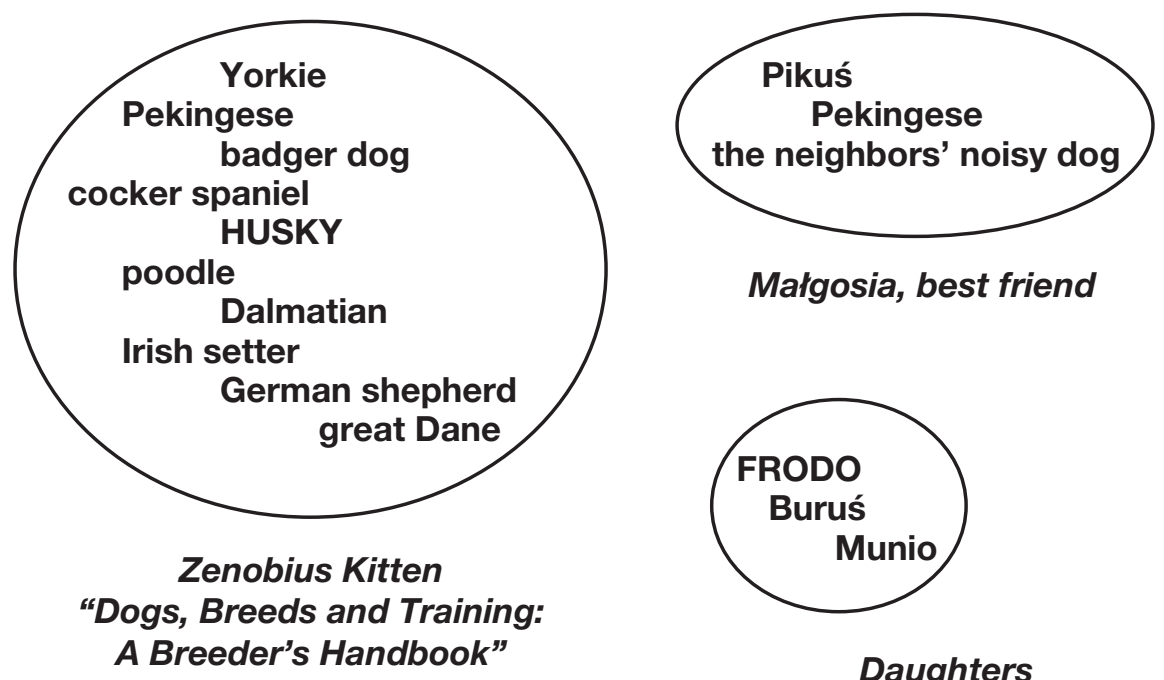

Małgosia, best friend

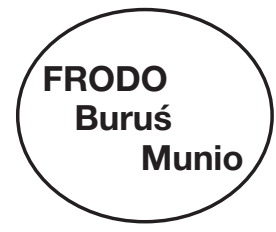

Daughters

and title in Figure 2 are fictitious), a childhood experience of being bitten by a particular dog called Pikuś, and current experience with her own dogs, which the author breeds and cares for with her daughters.

If cognitive representation is organized as described here, then the social context would definitely be important for the data processing speed, which should be reflected by classical indicators such as reaction times or error rates. In the example from Figure 1, the Pekingese should be recognized as a dog more quickly when the memories of a relationship with a friend (Pikuś was a Pekingese!) are activated than when the knowledge from Kitten's dog handbook is active (a Pekingese is not a very representative example of this concept). The data showing the role of context was collected during studies on the exemplarbased approach (Rosch, 1978); however, in the discursive model of mind, there is more to be said.

The object of knowledge constructed in different social contexts is seemingly the same; however, despite the same verbal etiquette, the subjective meaning of a concept varies, just like the detailed attributes of knowledge (see Table 1).

The example from Figure 1, 2 and Table 1 appears to be simple; however, it is a good illustration of the essence of the specificity of knowledge for social context, which - according to the discursive mind model - applies to a person's whole cognitive system. The aggregation of experience and knowledge in relatively 


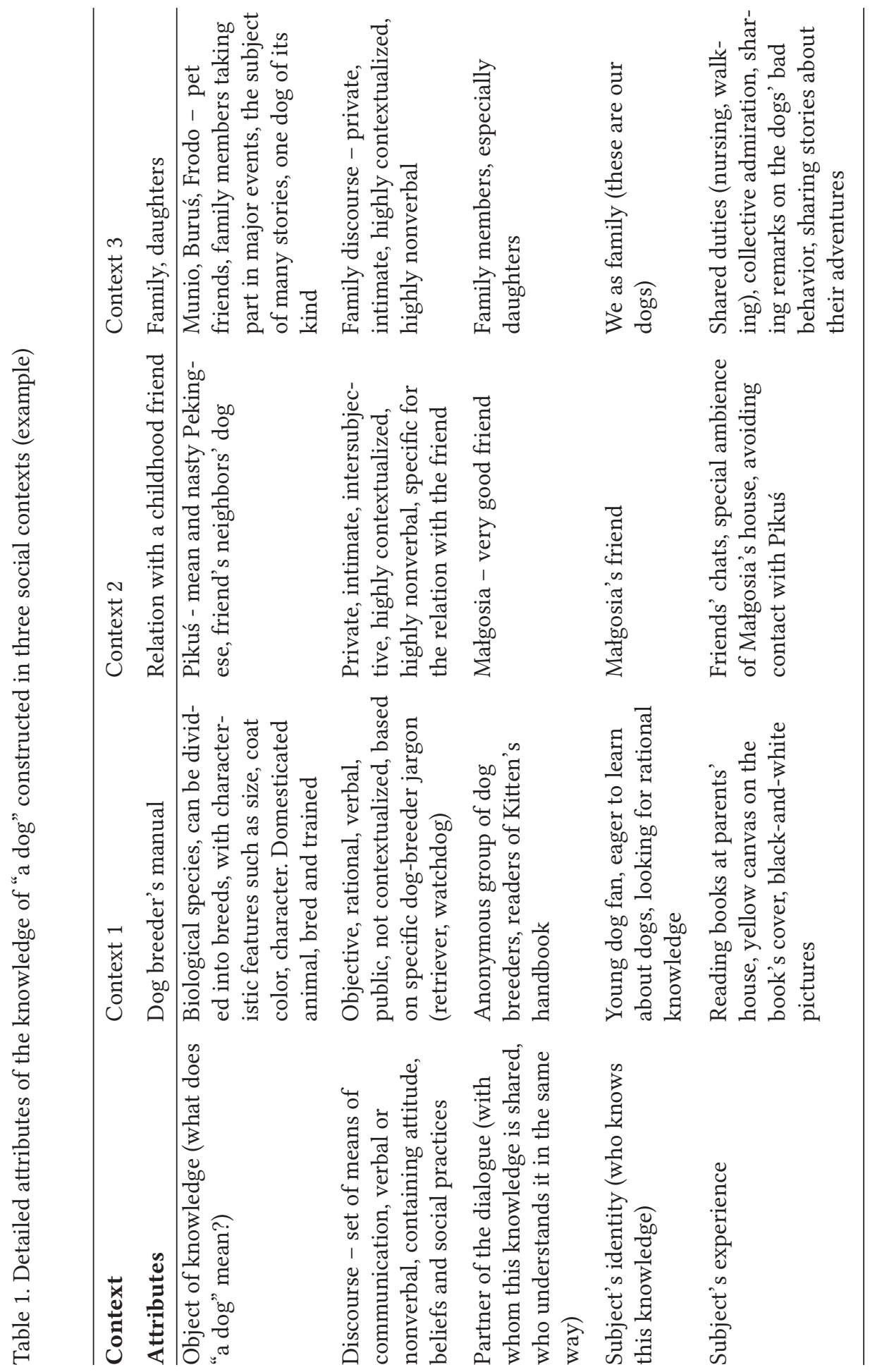


Figure 3. Representation of explicit and implicit knowledge in the discursive mind

\section{Discourse, relation, identities of a subject and partners (implicit cognition)}

\section{Social context}

Subject's

experience

(implicit cognition)

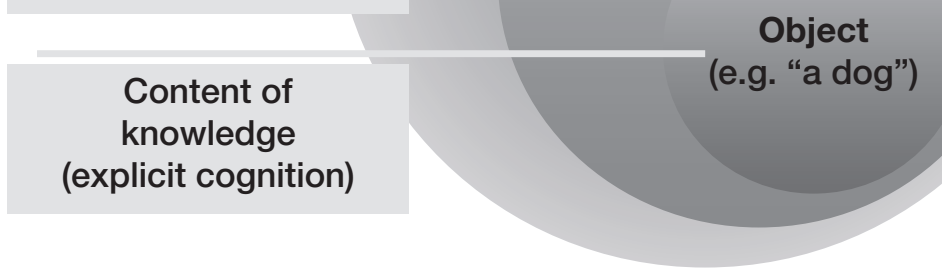

independent modules is the basis for the organization of cognitive structures, any of them being able to contain concepts and all other forms of cognitive representation - schemas, scripts, narrations or procedures. Each module carries cognitive-affective resources that emerged and developed in a certain social context - within relationships with parents, peers, children, bosses or colleagues. The number and characteristics of these modules are the inter-individual variable, depending on the course of primary and secondary socialization processes in the case of a particular person.

Being barely more than the tip of the iceberg, knowledge that is explicit and of which one is aware, is coated with the implicit. As shown in Figure 3, what envelops every piece of such explicit knowledge is the representation of personal experience. This stems from the social context in which it was acquired - relationships, being part of a group, growing up in a certain community. Personal implicit knowledge consists of the record of experience, which is theoretically accessible to the subject's awareness but usually remains under the threshold of his or her consciousness, being constantly engaged in processing information about an object of knowledge of which he or she is fully aware. This unit of representation also stores supra-individual, shared, inter-subjective, implicit knowledge, which concerns the social context and contains, among other things, the characteristics of interpersonal relationships in a given social circle as well as a representation of the identity of the subject and its partners ("who is who" in 
a certain relationship). It includes sets of beliefs and truths shared by members of this social circle. Figure 3 illustrates these ideas.

According to the discursive mind model, the I-positions proposed by the dialogical self theory are relatively autonomic modules of the cognitive system. They consist of script-like structures combining personal and socially shared knowledge. These structures are activated in certain conditions (automatically or intentionally ${ }^{4}$ ) and henceforth - until the next I-position is activated - determine the range of information processed and the specific rules of this processing.

\section{Personality - stable or labile?}

As we have previously discussed (Stemplewska-Żakowicz et al., 2010), as a consequence of its assumptions the discursive mind model offers an interesting approach to the classic problem of the stability vs. lability of personality. In this model, stability is, as in a range of other social-cognitive concepts, associated with a repertoire of knowledge structures latently existing in the mind. On the other hand, the model offers an explanation of lability in the sense that only some particular modules of that knowledge are activated at a given time. The distinctive feature of the discursive mind model, and the dialogical self theory (Hermans, 1996) by which it was inspired, is the essential role of the subject of knowledge. It means that when a specific module of knowledge (an I-position) is activated, a specific tool of information processing is launched and the consequential activation of a certain content of a self-image is just one of the results of this shift in information processing. It reflects the classic distinction of the Jamesian I and Me or "self-as-an-object" and "self-as-a-subject" and the new social-cognitive revision of these notions proposed by Greenwald and Pratkanis (1984).

The dialogical self theory has its origins in Hubert Hermans' (2001) perspective on the problem of personality stability and lability and his idea of merging the concepts of continuity and discontinuity of a person's subjective experience in one consistent theoretical construct. Comparing James' concept of I, consisting of different parts of the self (characters), to Bakhtin's polyphonic structure of the novel and the multiplicity of its characters, Hermans points out the similarity between these concepts, but on the other hand emphasizes the point of difference between the two approaches. This difference concerns the existence of one domi-

\footnotetext{
${ }^{4}$ Although the differentiation between automatic and intentional activation of the I-positions was described by some DST researchers, in this model the distinction is not fully applicable to describing how the knowledge structures are activated. We believe that the activation of I-position is rather an automatic process, which occurs in a certain situational context. Even if we consider a specific situation in which certain I-positions are activated during an intentional (in a way!) process of recalling some memories, we argue that the activation itself is automatic even though the process of recalling may be perceived as intentional. Whether we recall intentionally or due to the fact that the I-position, which has access to certain memories, has been automatically activated by external stimuli, is a question of philosophical debate rather than empirical verification and thus remains not covered by the model.
} 
nating I unifying all the parts of the self, which was assumed by James but ignored by Bakhtin. Hermans (2001) argues that these seemingly contradictory assumptions concerning the presence of the dominating I can, in fact, be both supported and even combined, bringing us to a description of the self as composed of many autonomous internally coherent centers of the interpretation of individual experience. Different subjects can interpret the experience from different perspectives.

As we have stated above, in the discursive mind the entire knowledge possessed by a person is always "someone's" knowledge. It is always constructed and used by a specific person of a specific identity. The subject of school knowledge is surely "a pupil", which may form an I-position in the discursive mind. The context in which this school knowledge was acquired is a relationship with a teacher and peers, in which such situations as being examined or studying for a test were natural and frequent. When an adult with such experience is later present in an entirely different context and tries to recall information acquired in school, the discursive mind automatically activates his or her identity as a pupil, and with it all the different expectations, beliefs and truths natural and implicit for the school context. These portions of implicit knowledge, even if currently inadequate, can still be activated while recalling portions of explicit school knowledge and may influence the way in which the current situation is experienced or alter behavior, even though the current context is far from the original school environment. A similar, also highly probable example can be found in the work of Wertsch (1991). These kinds of effects are more approachable from the perspective of the discursive mind model, because it describes relations between cognitive-affective units differently as compared to classic models. The network of mutual activation is based on the sharing of relational context and the identity of the subject, not on the resemblance of explicit knowledge content.

\section{The discursive mind model and the dialogical self theory: comparison}

The discursive mind model fulfills a proposed shift of the dialogical self theory closer to social-cognitive approaches to personality (Bąk, 2009). The dialogical self theory involves an approach that is hard to share with the social-cognitive approaches: It proposes a radical extension of the notion of self, which should include not only the inner content but also people or even institutions from the external world (Hermans \& Kempen 1993; Hermans \& Hermans-Jensen, 1995), while the cognitive theories of self consider other people as an important element of the self's development; their representations may influence the content of the self, but the inclusion of external persons in the self is impossible (Bąk, 2009). Similarly, the issue of divergence of self applies to comparisons between elements of the self-knowledge of a single indivisible subject in the social-cognitive approach, while the dialogical self theory implies many available subjects in- 
volved in a dynamic dialogue similar to real people's relations. Finally, a person's activity in social-cognitive approaches involves monitoring the discrepancies between standards of a unique subject: keeping small incoherencies between positive standards of the self and large discrepancies for negative standards. On the other hand, ideas - shared by the dialogical self theory - related to placing different standards of evaluation of the surroundings and the person in different subjects, with conflicts occurring between subjects and not inside the only subject, seem quite acceptable. According to Bąk (2009), the areas of interest of the two approaches are different: The social-cognitive theories concentrate on intra-psychological phenomena occurring for one subject, while the dialogical self theory focuses on interpersonal phenomena occurring between different subjects inside one person's mind. He points out that the concept of multiplicity of cognitive subjects can be accepted by the social-cognitive approaches when it acquires a reliable description in the cognitive terminology, using such notions as "cognitive system", "representations", "information processing" to describe structural and functional solutions inside the mind.

The proposed model of the discursive mind complements the three main assumptions of the theory with the above-mentioned structural and functional solutions, which meet the requirements of cognitive psychology and are consistent with the dialogical self theory. The three problematic issues are:

1. Volitional self. Hubert Hermans $(2003,2006)$ recognizes that the self moves between the I-positions volitionally, which enables the self to attach to different I-positions and gain their perspectives on interpreting experience. At the same time, the author highlights the lack of a central unit deciding which of the I-positions is currently given voice. This provokes a question: If the self is not a decisive unit, what role does its volitional character play in the theory? Is the process of giving voice to the I-positions dependent on the dialogues between them, or is the direction of action rather undertaken by the self, or do both factors apply?

2. Processes of giving voice to I-positions by the self. The process of giving voice to the I-positions by the self seems similar to the process of activation of cognitive structures, but this similarity is only superficial, because Hermans does not provide a description of the content of I-positions. Just as above, the processes of giving voice remain mainly a metaphor of interpersonal relations and refer to the intrapersonal level (Hermans, 1999b, 2004). From the point of view of cognitive psychology, it should be distinguished whether this is just a metaphor or not, and if it is not - what kind of particular processes it involves (Suszek et al., 2010).

3. The inner structure of the I-positions. This issue seems to remain beyond the scope of interest of the dialogical self theory's author. Despite the fact that Hermans suggests that the I-position includes some specific elements, such as individual beliefs, patterns of evaluating meanings, dominant emotions 
or general life perspectives, the way in which they might be located inside the I-position is not really described, apart from stating that they are stored as perspectives and metaphors. This is far from being satisfactorily precise.

These problematic issues are tackled by the discursive mind model. The problem of volitional self is solved entirely by abandoning the notion of self. This makes inapplicable the issue of the self giving voice. The model focuses on the third issue - the inner structure of positions. They are defined as modules of representation of experience. The modules do not have to be imaginatively given voice because as knowledge structures they can be evoked by external stimuli without the participation of the self. As a result, the model of the discursive mind provides reliable descriptions of processes proposed by the dialogical theory using terminology from the social-cognitive approach. For example, instead of "giving voice", it describes the activation of knowledge governed by the rules of the process of automatic activation of cognitive structures (for example notions, stereotypes, goals, see Bargh, 1994, 1997, 2006).

Apart from the different descriptions of content and rules of activating Ipositions and modules, there are other differences between the two approaches. The dialogical self theory highlights the aspect of communication between I-positions, which is defined by processes of dialogical accordance and discordance, while the discursive mind model brings more detail to it by presenting the limitations in communication as a result of different codes of recording knowledge in the modules.

The model of the discursive mind assumes that there are longitudinal modules which do not include higher levels of information processing and thus disable the verbalization of and conscious reflection on a personal experience, which corresponds to the idea of silent voices in the dialogical self theory. For example, the constitution of a silent I-position in the dialogical self theory suggests that this I-position is well developed and ready to be given voice by the self - it is just enough to make it more approachable to the self. It is different with the module, which is not sufficiently developed and requires being supported by the levels operating in the verbal code, which would enable conscious reflection on personal experience. Modules do not have to be on the bottom of the activation hierarchy, as is the case with the silent positions, and even though they do not have higher levels of representation they can still be easily evoked and influence the processes of giving meaning and interpreting experience, without the person's awareness. This is an important consideration for clinical practice, close to the psychotherapeutic traditions of healing through developing verbal possibilities of elaborating the implicit contents of unconsciousness. Also, therapists inspired by the dialogical self theory suggest that disorders may occur not only on the level of dialogue but also on the level of I-positions (Dimaggio \& Stiles, 2007), stating that the subjective I-position may be damaged. The dialogical self theory does not provide tools for understanding deficits inside I-positions. However, 
its advantage is a wide and complete description of relations between them, not presented in psychotherapeutic literature on such a level of detail.

The discursive mind model is also more precise compared to the I-position concept in conceptualizing the relations between a module and the external context. Modules are developed in relation to external carriers of discourse and can be activated by them. Hermans' theory refers to the imaginational inclusion of external objects into the I-position. It shows the role of imagination in conducting dialogues between the internal and external parts of the I-positions, so far underrated by researchers of the self, although the empirical verification of this phenomenon requires its further definition.

\section{Conclusion - toward experimental verification of the discursive mind model}

The discursive mind model, and particularly the assumption on the specificity of knowledge structures for the social context, can be acknowledged as worthy of precise theoretical description and empirical verification. This seems particularly important in the context of new trends in mainstream psychology that take greater account of phenomena of an inter-subjective nature (Higgins, 2000). The model of the discursive mind and the DST offer an attractive explanation of these kinds of social-cognitive phenomena.

The described model is characterized by great complexity. Such complexity makes unequivocal verification harder to perform. In an attempt to solve this problem, we used rigorous methodology and performed a series of experiments (for more information, see Suszek et al., 2010, Stemplewska-Żakowicz et al., 2012). These empirical studies were aimed at checking the effects of activation of different I-positions on cognitive processes and behavior. We showed that cognitive-affective resources of the I-positions activated in a particular context are more easily accessible than resources of the I-positions that are not activated. This effect was visible in several experimental measures, such as reaction times, error rates and others. Our results support the hypothesis that I-positions have their own specific cognitive-affective resources and that the main constructs of the DST, such as the I-position and positioning, are empirically real and can produce effects that are observable by means of empirical and experimental investigation. The model of the discursive mind and its empirical verification not only gives support to the DST but can also be a vehicle of its contribution to theories stemming from other theoretical traditions. In particular, the idea of placing a dialogue in sociocultural and relational contexts - as a basis for module formation in the mind - can be valuable in advancing general psychological understanding of cognition and personality.

The next step would be to describe how different modules in the discursive mind interact with each other, i.e. how different situations and circumstances 
prime the revelation of different pieces of knowledge and different ways of experience interpretation. We hope that future research in this direction can help us understand and capture the complexity and dynamics of the discursive mind.

\section{Acknowledgements}

Work on the paper was supported by research fund BST 1678/39/2013 provided by the University of Warsaw.

\section{References}

Andersen, S.M. \& Chen, S. (2002). The relational self: An interpersonal socialcognitive theory. Psychological Review, 109 (4), 619-645.

Bakhtin, M.M. (1984). Problems of Dostoevsky's Poetics (edited and translated by C. Emerson). Minneapolis: University of Minnesota Press.

Bandura, A. (1999). A social cognitive theory of personality. In L. Pervin \& O. John (Eds.), Handbook of Personality ( $2^{\text {nd }}$ edition, pp. 154-196). New York: Guilford Publications.

Bargh, J.A. (1994). The four horsemen of automaticity. Awareness, intention, efficiency and control in social cognition. In R.S. Wyer \& T.K. Srull (Eds.), Handbook of Social Cognition. Vol. 1 (pp. 1-40). Hillsdale, NJ: Erlbaum.

Bargh, J.A. (1997). The automaticity of everyday life. In R.S. Wyer, Jr. (Ed.), The Automaticity of Everyday Life: Advances in Social Cognition. Vol. 10 (pp. 1-61). Mahwah, NJ: Erlbaum.

Bargh, J.A. (2006). Social Psychology and the Unconscious: The Automaticity of Higher Mental Processes. Philadelphia, PA: Psychology Press.

Bąk, W. (2009). Wielość ja w ujęciu poznawczym i dialogowym: Próba integracji podejść [Inner multiplicity from cognitive and dialogical perspectives. An attempt at integration]. Przeglą Psychologiczny, 52 (1), 53-68.

Berger, P.L. \& Luckmann, T. (1966). The Social Construction of Reality: A Treatise in the Sociology of Knowledge. Garden City, NY: Anchor Books.

Billig, M. (1996). Arguing and Thinking: A Rhetorical Approach to Social Psychology $\left(2^{\text {nd }}\right.$ ed. revised). Cambridge: Cambridge University Press.

Chen, M. \& Bargh, J. (1997). Nonconscious behavioral confirmation processes: The self-fulfilling consequences of automatic stereotype activation. Journal of Experimental Social Psychology, 33 (5), 541-560.

Cervone, D. (2004). The architecture of personality. Psychological Review, 111 (1), 183-204.

Cervone, D., Caldwell, T.L., Fiori, M., Orom, H., Shadel, W.G., Kassel, J.D., \& Artistice, D. (2008). What underlines appraisals? Experimentally testing a Knowledge-and-Appraisal Model of personality architecture among smokers contemplating high-risk situations. Fournal of Personality, 76 (4), 929-967. 
Cosmides, L. \& Tooby, J. (1992). Cognitive adaptations for social exchange. In J. Barkow, L. Cosmides, \& J. Tooby (Eds.), The Adapted Mind. Evolutionary Psychology and the Generation of Culture (pp. 163-228). New York: Oxford University Press.

Cosmides, L. \& Tooby, J. (1994). Origins of domain-specificity. The evolution of functional organization. In L.A. Hirschfeld \& S.A. Gelman (Eds.), Mapping the Mind. Domain Specificity in Cognition and Culture (pp. 85-116). Cambridge: Cambridge University Press.

Dimaggio, G. \& Stiles, W.B. (2007). Psychotherapy in light of internal multiplicity. Journal of Clinical Psychology, 63 (2), 119-127.

Edwards, D. \& Potter, J. (1992). Discursive Psychology. London: Sage.

Epstein S. (1991). Cognitive-experiential self theory: An integrative theory of personality In R. Curtis (Ed.), The Relational Self. Theoretical Convergences in Psychoanalysis and Social Psychology. New York: Guilford Press.

Fodor, J.A. (1983). The Modularity of Mind. Cambridge: MIT Press.

Fodor, J.A. (2000). The Mind Doesn't Work That Way: The Scope and Limits of Computational Psychology. Cambridge, MA: MIT Press.

Forgas, J.P. (1981). Social Cognition: Perspectives on Everyday Understanding. London: Academic Press.

Forgas, J.P. \& Williams, K.D. (2002). The Social Self. New York: Psychology Press. Gazzaniga, M.S. \& LeDoux, J.E. (1978). The Integrated Mind. New York: Plenum Press.

Gergen, K.J. (1991). The Saturated Self. Dilemmas of Identity in Contemporary Life. New York: Basic Books.

Greenwald, A.G. (1982). Is anyone in charge? Personalysis vs. the principle of personal unity. In J. Suls (Ed.), Psychological Perspectives on the Self. Vol. 1 (pp. 151-181). Hillsdale, NJ: Erlbaum.

Greenwald, A.G. (1988). Self-knowledge and self-deception. In J.S. Lockard \& D.L. Paulhus (Ed.), Self-Deception: An Adaptive Mechanism? (pp. 113-131). Englewood Cliffs, NJ: Prentice-Hall.

Greenwald, A.G. \& Banaji, M.R. (1995). Implicit social cognition: Attitudes, selfesteem, and stereotypes. Psychological Review, 102 (1), 4-27.

Greenwald, A.G. \& Pratkanis, A.R. (1984). The self. In R.S. Wyer \& T.K. Srull (Eds.), Handbook of Social Cognition (pp. 129-178). Hillsdale, New York: Erlbaum.

Hardin C.D. \& Higgins E.T. (1996). Shared reality: How social verification makes the subjective objective. In R.M. Sorrentino \& E.T. Higgins (Eds.), Handbook of Motivation and Cognition. Vol. 3: The Interpersonal Context (pp. 28-84). New York: Guilford.

Harré, R. \& Gillett, G. (1994). The Discursive Mind. London: Sage.

Harré, R. \& van Langenhove, L. (1999). Positioning Theory: Moral Contexts of Intentional Action. Oxford: Blackwell. 
Hermans, H.J.M. (1996). Voicing the self: From information processing to dialogical interchange. Psychological Bulletin, 19 (1), 31-50.

Hermans, H.J.M. (1999). The polyphony of the mind: A multivoiced and dialogical self. In J. Rowan \& M. Cooper (Eds.), The Plural Self. Multiplicity in Everyday Life (pp. 107-131). London: Sage.

Hermans, H.J.M. (2001). Conceptions of self and identity: Toward a dialogical view. International fournal of Education and Religion, 2 (1), 43-62.

Hermans, H.J.M. (2003). The construction and reconstruction of a dialogical self. Journal of Constructivist Psychology, 16 (2), 89-130.

Hermans, H.J.M. (2004). The dialogical self: Between exchange and power. In H.J.M. Hermans \& G. Dimaggio (Eds.), The Dialogical Self in Psychotherapy (pp. 13-28). New York: Brunner-Routlege.

Hermans, H.J.M. (2006). The self as a theater of voices: Disorganization and reorganization of position repertoire. Journal of Constructivist Psychology, 19 (2), 147-169.

Hermans, H.J.M. \& Kempen, H.J.G. (1993). The Dialogical Self: Meaning as Movement. San Diego, CA: Academic Press.

Hermans, H.J.M. \& Hernans-Jensen, E. (1995). Self-Narratives. The Construction of Meaning in Psychotherapy. New York: Guilford.

Hermans, H.J.M. \& Hermans-Konopka, A. (2010). Dialogical Self Theory. Positioning and Counter-Positioning in a Globalizing Society. Cambridge: Cambridge University Press.

Higgins, E.T. (2000). Social cognition: Learning about what matters in the social world. European fournal of Social Psychology, 30 (1), 3-39.

Jost, J.T. \& Kruglanski, A.W. (2002). The estrangement of social constructionism and experimental social psychology: history of the rift and prospects for reconciliation. Personality and Social Psychology Review, 6 (3), 168-188.

Kruglanski, A.W. (1996). Motivated social cognition: Principles of the interface. In E.T. Higgins \& A.W. Kruglanski (Eds.), Social Psychology: Handbook of Basic Principles (pp. 493-520). New York: Guilford Press.

Markus, H. (1977). Self-schemata and processing information about the self. Journal of Personality and Social Psychology, 35 (2), 63-78.

Minsky, M. (1985). The Society of Mind. New York: Simon \& Schuster.

Moskowitz, G.B. (2005). Social Cognition: Understanding Self and Others. Guilford Press.

Nowak, A., Vallacher, R.R., Tesser, A., \& Borkowski, W. (2000). Society of self: The emergence of collective properties of self-Structure. Psychological Review, 107 (1), 39-61.

Pervin, L.A. \& John, O.P. (2001). Personality: Theory and Research. 8th ed. New York: John Wiley \& Sons.

Stemplewska-Żakowicz, K. (2001). Umysł dyskursywny. Propozycje teoretyczne podejścia dyskursywnego $\mathrm{w}$ psychologii [The discursive mind. Theoretical 
proposals of the discursive approach in psychology]. In I. Kurcz \& J. Bobryk (Eds.), Psychologiczne studia nad językiem i dyskursem [Psychological Studies on Language and Discourse] (pp. 195-228). Warsaw: PAN Psychology Institute Press.

Stemplewska-Żakowicz, K. (2004). O rzeczach widywanych na obrazkach i opowiadanych o nich historiach. TAT jako metoda badawcza i diagnostyczna [On Things which Have Been Seen in Pictures and Stories which Have Been Told about Them. The Thematic Apperception Test as a Research and Diagnostic Method]. Warsaw: Academica.

Stemplewska-Żakowicz, K., Suszek, H., Kobylińska, D., \& Szymczyk, B. (2010). Explorations in the discursive mind. Theoretical model. International fournal for Dialogical Science, 4 (1), 81-94.

Stemplewska-Żakowicz, K., Zalewski, B., Suszek, H., Fira-Krempa, E., \& Kobylińska, D. (2009). Relacyjnie strukturalizowany umysł. Model Teoretyczny [Relationally structured mind. A theoretical model]. Przeglad Psychologiczny, 52 (1), 69-85.

Stemplewska-Żakowicz, K., Zalewski, B., Suszek, H., \& Kobylińska, D. (2012). Cognitive architecture of the dialogical mind: An experimental approach. In H.J.M. Hermans \& T. Gieser (Eds.), Handbook on the Dialogical Self (pp. 264283). Cambridge: Cambridge University Press.

Suszek, H., Kobylińska, D., Stemplewska-Żakowicz, K., \& Szymczyk, B. (2010). Explorations in the discursive mind. Research. International fournal for Dialogical Science, 4 (1), 95-122.

Underwood, G. (1996). Implicit Cognition. Oxford: Oxford University Press.

Van Dijk, T.A. (1989). Social cognition and discourse. In H. Giles \& R.P. Robinson (Eds.), Handbook of Social Psychology and Language (pp. 163-183). Chichester: Wiley.

Van Dijk, T.A. (1997). Discourse as Structure and Process. London: Sage.

Van Dijk, T.A. (2007). The study of discourse: An introduction. In T.A. van Dijk (Ed.), Discourse Studies. 5 Vols. (Sage Benchmark Series, pp. xix-xiii). London: Sage.

Van Dijk, T.A. (2008). Discourse and Context. A Sociocognitive Approach. Cambridge: Cambridge University Press.

Vygotsky, L.S. (1982). Thought and Language. Cambridge, MA: MIT Press.

Wertsch, J.V. (1991). Voices of the Mind. A Sociocultural Approach to Mediated Action. Cambridge, MA: Harvard. 